\title{
MONOTONICITY OF THE JENSEN FUNCTIONAL FOR $f$ - DIVERGENCES WITH APPLICATIONS TO THE ZIPF-MANDELBROT LAW
}

\author{
Neda LovričEvić, Đilda PeČARIĆ AND Josip PeČARIĆ
}

\begin{abstract}
The Jensen functional in its discrete form is brought in relation to the Csiszár divergence functional via its monotonicity property. Thus deduced general results branch into specific forms for some of the well known $f$ - divergences, e.g. the Kullback-Leibler divergence, the Hellinger distance, the Bhattacharyya coefficient, $\chi^{2}-$ divergence, total variation distance. Obtained comparative inequalities are also interpreted in the environment of the Zipf and the Zipf-Mandelbrot law.
\end{abstract}

Mathematics subject classification (2010): 94A15, 94A17, 26D15, 26 A51.

Keywords and phrases: Monotonicity property, Jensen's functional, Zipf's and Zipf-Mandelbrot's law, Csiszár divergence functional, $f$ - divergences.

\section{REFERENCES}

[1] I. CSISZÁR, Information-type measures of difference of probability functions and indirect observations, Studia Sci. Math. Hungar., 2 (1967), 299-318.

[2] I. Csiszár, Information measures: A critical survey, Trans. 7th Prague Conf. on Info. Th. Statist. Decis. Funct., Random Processes and 8th European Meeting of Statist., Volume B, Academia Prague, 1978, 73-86.

[3] S. S. DRAGOMIR, Some inequalities for the Csiszár $\Phi$ - divergence, RGMIA.

[4] L. EgGhe, R. Rousseau, Introduction to Informetrics. Quantitative Methods in Library, Documentation and Information Scince, Elsevier Science Publishers, New York, (1990).

[5] T. van Erven, P. Harremoës, Rényi Divergence and Kullback-Leibler Divergence, Journal of Latex Class Files, 61 (2007); arXiv: 1206.2459v2 [cs.IT]24 April 2014.

[6] S. Kullback, Information Theory and Statistics, J.Wiley, New York, 1959.

[7] S. Kullback, R. A. Leibler, On information and sufficiency, Annals of Mathematical Statistics, 221 (1951), 79-86.

[8] N. LovričEvić, Đ. PeČArić, J. PeČARIĆ, Zipf-Mandelbrot law, f-divergences and the Jensentype interpolating inequalities, J. Inequal. Appl. (2018) 2018:36 https://doi.org/10.1186/s13660-018$1625-\mathrm{y}$

[9] B. Manaris, D. Vaughan, C. S. Wagner, J. Romero, R. B. Davis, Evolutionary Music and the Zipf-Mandelbrot Law: Developing Fitness Functions for Pleasant Music, Proceedings of 1st European Workshop on Evolutionary Music and Art (EvoMUSART2003), 522-534.

[10] B. MAndelbrot, An informational theory of the statistical structure of language, In Jackson, W., editor, Communication Theory, New York, Academic Press, 1953., 486-502.

[11] B. MandelB Rot, Information Theory and Psycholinguistics, in Wolman, B.B., and Nagel, E. (eds.), Scientific psychology, Basic Books, 1965.

[12] D. Yu. Manin, Mandelbrot's Model for Zipf's Law: Can Mandelbrot's Model Explain Zipf's Law for Language?, Journal of Quantitative Linguistics, 163 (2009), 274-285.

[13] D. S. Mitrinović, J. E. PeČAriĆ, A. M. FinK, Classical and New Inequalities in Analysis, Kluwer Academic Publishers, Dordrecht/Boston/London, 1993. 
[14] M. A. Montemurro, Beyond the Zipf-Mandelbrot law in quantitative linguistics, URL:arxiv:condmat/0104066v2, (2001).

[15] D. Mouillot, A. LePretre, Introduction of relative abundance distribution (RAD) indices, estimated from the rank-frequency diagrams(RFD), to assess changes in community diversity, Environmental Monitoring and Assessment, Springer 63 (2) (2000), 279-295.

[16] Z. K. SilagadZe, Citations and the Zipf-Mandelbrot Law, Complex Systems, 11 (1997), 487-499. 